\title{
DIVERSIDADE E ECOLOGIA DOS CAMARÕES DE ÁGUA-DOCE (CRUSTACEA PALAEMONIDAE E ATYIDAE) NO BAIXO SÃO FRANCISCO (NORDESTE DO BRASIL)
}

\author{
Santos, L.V.R ${ }^{1,}$; Silva, E.L. ${ }^{1}$; Barros, F.P.A. ${ }^{1}$; Gonçalves, A.P. ${ }^{1}$; Pinto, T.K. ${ }^{2}$ \& Coelho-Filho, P.A. ${ }^{1}$ \\ ${ }^{1}$ Universidade Federal de Alagoas (UFAL), Campus Arapiraca, Laboratório de Carcinologia. \\ ${ }^{2}$ Universidade Federal de Alagoas (UFAL), Campus Arapiraca, Laboratório de Ecologia Bentônica. \\ *Autor correspondente: bioluciia.vanessa@gmail.com
}

\begin{abstract}
Este trabalho teve por objetivo determinar a composição taxonômica dos camarões dulceaquícolas (Crustacea, Decapoda) no Baixo Rio São Francisco (Nordeste do Brasil), suas relações ecológicas e distribucionais, caracterizando o habitat e as variações espaço-temporais dessa comunidade. Foram realizados monitoramentos bimestrais entre dezembro de 2015 e outubro de 2017 em 8 áreas distintas do baixo São Francisco, desde Piranhas (AL) até Piaçabuçu (AL), próximo a foz do Rio. Os exemplares foram recolhidos através de armadilhas de fundo (covos), puçás e coletas manuais. A fauna esteve representada por Macrobrachium acanthurus, $M$. amazonicum, M. carcinus, M. jelskii e M. olfersii, da família Palaemonidae, e Atya gabonenses, Atya scabra e Potimirim potimirim, da família Atyidae. Destacam-se A. scabra e M. amazonicum, por serem citadas pela primeira vez na área de estudo. M. amazonicum é uma espécie exótica para a bacia do Rio São Francisco, e apesar de ocorrer na maioria das amostragens, apresentou um baixo número de espécimes, devido possivelmente a possíveis interações antagônicas com as espécies nativas da bacia. Foi clara a distinção de áreas de ocorrência devido principalmente ao tipo de substrato preferencial - áreas a montante de Traipu possuem maior disponibilidade de substratos rochosos do que as áreas a jusante, próximas à planície fluviomarinha. Assim, A. gabonenses, A. scabra, $M$. carcinus e $M$. olfersii têm o substrato rochoso como biótopo preferencial, biótopo esse abundante a montante de Traipu (AL), enquanto que $M$. acanthurus, M. amazonicum, M. jelskii e P. Potimirim ocorrem no biótopo vegetação (macrófita). A medida que se aproxima da foz do Rio, as características hidrológicas se modificam devido a gradativa influência marinha, influenciando diretamente na composição e abundância da fauna estudada e promovendo uma redução considerável da ocorrência de todos os táxons com a aproximação da foz. Com a diminuição da vazão do Rio São Francisco, principalmente após 2015, ocorreram importantes alterações nas características hidrológicas e na disponibilidade de hábitats para as espécies, tendo como consequência direta a diminuição na abundância de $A$. gabonenses e A. scabra, até que a partir de março de 2017, essas espécies não foram mais capturadas.
\end{abstract}

Palavras-chave: composição faunística, biodiversidade, camarões dulcícolas. 